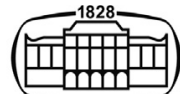

AKADÉMIAI KIADÓ

Acta Veterinaria

Hungarica

$68(2020) 4,370-373$

Dol:

$10.1556 / 004.2020 .00060$

(C) 2021 The Author(s)

ORIGINAL RESEARCH

PAPER

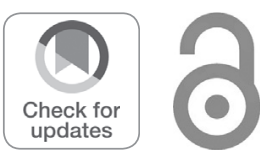

\title{
Lithium chloride outperformed oxalic acid sublimation in a preliminary experiment for Varroa mite control in pre-wintering honey bee colonies
}

\author{
ÉVA KOLICS ${ }^{1,2}$, ANDRÁS SPECZIÁR ${ }^{3}$, JÁNOS TALLER ${ }^{1}$, \\ KINGA KLÁRA MÁTYÁS ${ }^{1}$ and BALÁZS KOLICS ${ }^{1,2 *} \odot$ \\ ${ }^{1}$ Department of Plant Sciences and Biotechnology, Georgikon Faculty, University of Pannonia, \\ Festetics u. 7, H-8360 Keszthely, Hungary \\ ${ }^{2}$ Kolics Apiaries, Balatonszentgyörgy and Bolhó, Balatonszentgyörgy, Hungary \\ ${ }^{3}$ Balaton Limnological Institute, Centre for Ecological Research, Tihany, Hungary
}

Received: June 24, 2020 - Accepted: October 30, 2020

Published online: January 16, 2021

\begin{abstract}
Since lithium salts were demonstrated to be very effective for the potential control of Varroa destructor, a highly detrimental parasite of honey bee (Apis mellifera), no studies have been reported on their comparison with any commonly used varroicides in commercial bee colonies. In this study we compared the effectiveness of lithium chloride to that of oxalic acid, a widely used miticide. The results of the present study confirm that lithium has superior efficacy to oxalic acid sublimation both as a main or a supplementary pre-wintering treatment at moderate infestation levels, restricted to certain prewintering conditions. Considering its easy implementation in apicultural practice and its twofold mode of action, trickling would be the preferred way of administration after the use of lithium salts as varroicides is authorised.
\end{abstract}

\section{KEYWORDS}

lithium chloride, oxalic acid, sublimation, contact effect, honey bee, Apis mellifera, Varroa

\section{INTRODUCTION}

When left untreated, Varroa destructor can kill an entire colony within one or two years (Spivak and Reuter, 2005; Barlow and Fell, 2006); however, in areas with high bee density this may occur within a single apicultural season. Therefore, this parasitic mite is recognised as the biggest threat to the western honey bee worldwide. Control methods can be effective but are restricted to only a few chemicals, implying the potential development of acaricide resistance (Mozes-Koch et al., 2000; Spreafico et al., 2001) and reducing the possibility of mite eradication in the foreseeable future. Parallel to this, there is an increasing demand to avoid the build-up of miticide residues or their metabolites in honey and beeswax (Smithberg and Dixit, 1982).

Organic acids and essential oils may be inconsistent in their efficacy (Rosenkranz et al., 2010), with the exception of oxalic acid (OA), which is often applied to colonies by dripping a solution of $\mathrm{OA}$ and sugar water between the frames of the hives at a typical application rate of 20-50 mL per colony in Central Europe, depending on climatic regions (Rademacher and Harz, 2006). However, there are numerous reports of recipes recommending different concentrations up to 3.5-6\%, also depending on the climatic regions in Europe (Rademacher and Harz, 2006), above which the mortality rates increase in bees. In Hungary, which has one of 
the highest bee densities in Europe, sublimation of OA is considered to be one of the most effective miticide treatments in apicultural practice. However, it affects only phoretic mites present on adult hive bees, therefore optimal treatment requires broodless colonies while the duration of its effectiveness is limited to approximately 7-8 days (Mutinelli et al., 1997).

Recently, it has been observed that lithium salts serve as a promising and easy-to-use alternative for the effective treatment of Varroa infestation (Ziegelmann et al., 2018; Stanimirovic et al., 2019). Furthermore, in some treatments $100 \%$ mite mortality was found in the brood-free period with minor or no mortality of adult bees with certain concentrations of lithium-containing chemicals (Ziegelmann et al., 2018; Stanimirovic et al., 2019). High miticidal activity was observed in artificial swarms after the application of 25 $\mathrm{mM}$ and $50 \mathrm{mM}$ lithium chloride $(\mathrm{LiCl})$ in sugar syrup and patties, respectively (Kolics et al., 2019; Ziegelmann et al., 2019).

To compare its miticidal performance with OA, we performed pre-wintering $\mathrm{LiCl}$ treatments on broodless commercial bee colonies.

\section{MATERIALS AND METHODS}

In the experiment carried out at the Georgikon Faculty of the University of Pannonia (Keszthely, Hungary $46^{\circ} 45^{\prime} 04.2^{\prime \prime} \mathrm{N} 17^{\circ} 14^{\prime} 02.3^{\prime \prime} \mathrm{E}$ ) in late autumn, altogether 26 fully developed queenright colonies were used, uniformly occupying nine to ten frames (comb size $24.5 \times 39.5 \mathrm{~cm}$, Hungarian standard 'Hunor'). The distance between the hives was $3 \mathrm{~m}$. Wire screens installed above the boards served to prevent the bees from coming into contact with the fallen mites and hive debris. Dead mites were counted daily, and sticky boards were cleaned.

Three types of experiments were carried out to compare the effect of $\mathrm{LiCl}$ and $\mathrm{OA}$ on mites in honey bee colonies.

E1) $\mathrm{LiCl}$ was applied in nine colonies with the treatment initiated on 26 October followed by an 11-day observation period, then supplemented with OA treatment initiated on 6 November followed by a 8-day observation period.

E2) OA treatment was applied in four colonies, initiated on 5 November followed by a 8-day observation period and then supplemented with $\mathrm{LiCl}$ treatment initiated on 14 November followed by an 11-day observation period.

E3) $\mathrm{LiCl}$ treatment was applied in 13 colonies, initiated on 11 December and then monitored for 11 and further 8 days without any additional treatment.

At the end of each trial, powder sugar test was performed on $100 \mathrm{~g}$ of randomly sampled bees from each hive (Deutschen Imkerbund, 2013). LiCl (lithium chloride hydrate, Szkarabeusz Kft., Pécs, Hungary) administration was carried out with trickling $40 \mathrm{~mL}$ of $250 \mathrm{mM}$ lithiated sugar syrup. OA was administered using Sublimox ${ }^{\circledR}$ equipment (model
APF01, Ditta Engineering Service, Italy) applying $2 \mathrm{~g}$ of oxalic aid acid dihydrate per colony per application (Szkarabeusz Kft., Pécs, Hungary). All hives were broodless during the whole period of the experiment.

Based on the three experimental setups we differentiated five treatment types: 1) $\mathrm{LiCl}$ applied first, as main treatment, in both E1 and E3 (differentiated in statistical analysis); 2) OA applied first, as main treatment, in E2; 3) $\mathrm{LiCl}$ applied second, as supplementary treatment, in E2; 4) OA applied second, as supplementary treatment, in E1; and 5) the residual effect of $\mathrm{LiCl}$ main treatment, monitored between days 11 and 19, in E3. The effect of each treatment was quantified by the cumulative number of mites found dead at the hive bottom insert relative to the total number of mites dropped during the 19 days of the experiments. Differences among treatment types were evaluated using non-parametric Kruskal-Wallis ANOVA by ranks followed by Mann-Whitney U post hoc tests. All statistical analyses were performed with the Statistica 8.0 software (statsoft.com).

\section{RESULTS}

\section{Lithium chloride proved to be more effective against Varroa mites, either alone or in combination, than oxalic acid}

In comparative experiments, the efficiency of miticide treatments varied significantly depending on the type $(\mathrm{LiCl}$ vs. OA) and method (main vs. supplementary) of treatment applied (Kruskall-Wallis ANOVA, d.f. $=5, n=52, \mathrm{H}=$ 40.7, $P<0.001$ ) (Fig. 1). The average numbers of fallen mites counted per colony are presented in Table 1.

The first two experiments (E1 and E2) involved an $\mathrm{LiCl}$ and an OA treatment, although in a reverse order, and thus, were considered to be comparable regarding their cumulative effect on mites. Substantially higher percentages of mites died during the $\mathrm{LiCl}$ main treatment in $\mathrm{E} 1$ (mean 95.6\%) than during the OA main treatment in E2 (58.7\%) (Fig. 1). Lithium chloride also surpassed OA in efficiency as a supplementary treatment: $41.3 \%$ of mites died during the supplementary $\mathrm{LiCl}$ treatment in E2, compared to the $4.4 \%$ mite mortality during the supplementary OA treatment in E1. In addition, there was no difference in the percentage of mites that died during the OA main treatment and $\mathrm{LiCl}$ supplementary treatment in E2. A bee mortality of about 200 individuals on average was observed when lithium treatment was followed by OA main treatment (E2), while no significant mortality occurred in the other treatment set-ups.

The third experiment (E3) revealed that the $\mathrm{LiCl}$ main treatment had a prolonged effect extending well beyond the 11 -day monitoring period set in advance; $84.2 \%$ of mites were killed during the first 11 days and an additional $15.8 \%$ during the subsequent eight days (from day 11 to day 19 after treatment. Moreover, this prolonged effect did not differ from the effect of the supplementary OA treatment in 


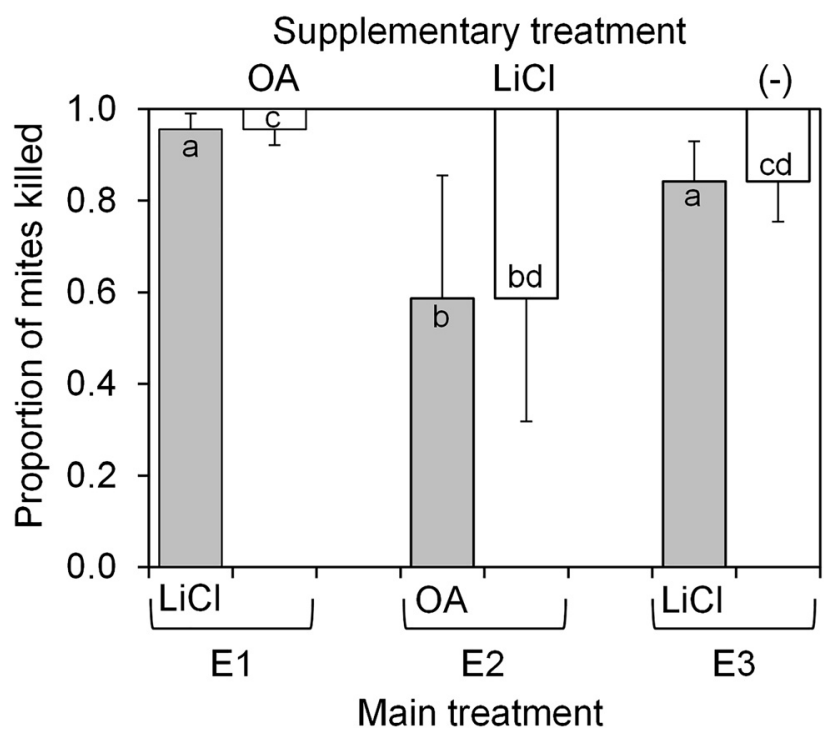

Fig. 1. Lithium chloride $(\mathrm{LiCl})$ is more effective in controlling Varroa destructor parasite in honey bee colonies (per cent of mites killed $\pm 95 \%$ confidence interval) than oxalic acid (OA), either applied as main or supplementary treatment (Kruskal-Wallis analysis of variance, $\mathrm{H}$ (d.f. $=5, n=52)=40.7, P<0.001$ ). Values not sharing any letter are statistically different at $P<0.05$ (MannWhitney U post hoc test). E1, E2 and E3 represent different experiments as specified in the text

Table 1. Average mite fall counted on the sticky board reveals that lithium chloride exerts superior miticidal effectiveness to oxalic acid in brood-free pre-wintering honey bee colonies as either a main or a supplementary treatment, and it shows prolonged effectiveness after a single treatment

\begin{tabular}{|c|c|c|c|}
\hline Treatment & E1 & E2 & E3 \\
\hline Date of start & 26 October & $\begin{array}{c}5 \\
\text { November }\end{array}$ & $\begin{array}{c}11 \\
\text { December }\end{array}$ \\
\hline Number of hives & 9 & 4 & 13 \\
\hline Main treatment & $\begin{array}{l}\text { Lithium } \\
\text { chloride }\end{array}$ & Oxalic acid & $\begin{array}{l}\text { Lithium } \\
\text { chloride }\end{array}$ \\
\hline Observation period (days) & 11 & 8 & 11 \\
\hline $\begin{array}{l}\text { Average number of mites } \\
\text { counted per hive }\end{array}$ & 65 & 78 & 28 \\
\hline Control treatment & Oxalic acid & $\begin{array}{l}\text { Lithium } \\
\text { chloride }\end{array}$ & $\begin{array}{l}\text { Lithium } \\
\text { chloride }\end{array}$ \\
\hline Observation period (days) & 8 & 11 & 8 \\
\hline $\begin{array}{l}\text { Average number of mites } \\
\text { counted per hive }\end{array}$ & 2 & 122 & 6 \\
\hline
\end{tabular}

E1, which, in addition, also included a residual effect from a preceding $\mathrm{LiCl}$ main treatment.

All colonies in the experiment overwintered successfully. No significant bee mortality was observed during the winter in any of the colonies.

\section{DISCUSSION}

Comparative experiments with pre-wintering bee colonies showed that LiCl trickling, used either as main or as supplementary treatment, has a superior efficacy to the widely applied OA treatment in the control of the parasitic mite $V$. destructor. The better performance of $\mathrm{LiCl}$ was supported by its long-lasting effectiveness and alternative action mechanisms. Compared to OA with an estimated duration of efficacy of 7-8 days (Mutinelli et al., 1997), we found that $\mathrm{LiCl}$ administered by trickling could be effective for at least to 1520 days. This attribute of $\mathrm{LiCl}$, and probably of other lithium salts, is in accordance with the previous observations (Kolics et al., 2020).

It was found that the lithium ion itself is the effective component of any lithium salts previously studied (Ziegelmann et al., 2018), and as an ion it is unlikely to be decomposed. In their original experiments, Ziegelmann et al. (2018) administered $\mathrm{LiCl}$ to bees in sugar syrup feed and described its systemic mode of action. Recently, Kolics et al. (2020) have proved that $\mathrm{LiCl}$ is a very efficient contact varroicide in a wide concentration range. The alternative modes of action of $\mathrm{LiCl}$ support its flexible application and facilitate the adjustment of treatment methods to various practical considerations. In this study, the method of trickling with a low amount of sugar syrup was chosen because, compared to administration by feeding used in previous studies (Ziegelmann et al., 2018; Stanimirovic et al., 2019), it may represent a lower risk of contamination to capped honey, and it may support both the systemic and the contact modes of actions simultaneously. Since $\mathrm{LiCl}$ was administered by trickling of lithiated sugar syrup within the effective concentration range of both the systemic (Ziegelmann et al., 2018) and the contact modes of action (Kolics et al., 2020) into the bees' space, it could act as a contact agent in bees directly reached by trickling and as a systemic agent in bees consuming it from the hive wall or from other bees. Moreover, since bees show advanced social behaviour, they distribute the lithiated sugar syrup within the entire colony by their physical contacts and social feeding, and consequently, expand the range of both contact and systemic effects of $\mathrm{LiCl}$ to all mites in the hive.

Lithium chloride may be especially efficient in controlling mites in bee colonies in the pre-wintering brood-free periods. At that life stage, the side effects of the treatment to bees seem to be minimal. For instance, in this study all experimental colonies overwintered successfully and developed similarly as the traditionally treated (control) ones. Concerning these issues, based on the absence of any sign that lithium affected the brood in late winter, we presume that the hive had become decontaminated by the onset of the broodright period. On the other hand, $\mathrm{LiCl}$ may be lethal to open brood, and it was reported to reduce the life span of adult bees in certain situations (Ziegelmann et al., 2018). Nevertheless, its possible accumulation and decontamination within the colony and especially in the honey needs extensive research.

In the present preliminary study, $\mathrm{LiCl}$ showed a highly potent and prolonged varroicidal effect. Although at present $\mathrm{LiCl}$ is one of the most promising tools for controlling the Varroa mite parasite jeopardising honey bee colonies all over the world, there are still many questions to be solved 
before its authorisation and wide-scale establishment in apiculture. Based on our preliminary observations on the post-treatment dynamics of mite fall in the pre-wintering period, we suppose that temperature may have a significant impact on the duration of efficacy and decontamination of $\mathrm{LiCl}$. This assumption is supported also by the fact that the inter-individual transfer of lithium within the bee colony is also inevitably influenced by temperature. Furthermore, if brood is present, part of the lithium administered is likely to be passed on to them by feeding and, consequently, the effective concentration of $\mathrm{LiCl}$ remaining available for share by infected adult bees in the colony will be lower. All these features of $\mathrm{LiCl}$ raise the question that under which conditions and at what timing relative to $\mathrm{LiCl}$ treatment $\mathrm{OA}$ can be applied. As OA is still one of the most accepted and widely used miticidal agents, its complete or partial substitution in apicultural practice should be handled with the greatest care.

Experimenting with miticidal treatments on dynamic bee colonies may be challenging, and most importantly, the recruitment of mites and their exposure to the treatment agent should be controlled. Therefore, the investigations were restricted to a late autumn pre-wintering, brood-free stage of bee colonies. In addition, residual mite abundance was checked by post-experiment powder sugar tests. These tests did not yield any mites, indicating a rather low residual mite abundance and significant treatment efficacy. The above methodological restriction, however, limits our knowledge on the efficacy under different conditions or at elevated infestation levels, as well as on the eventual side effects of $\mathrm{LiCl}$, especially on brood in the reproductive season.

Further research is needed to determine the optimum concentration and the most optimal administration method and frequency required for efficacy, which depends on environmental temperature and may be altered by humidity conditions. Moreover, extensive research is required to quantify eventual side effects on brood and the impacts related to chemical residues.

\section{ACKNOWLEDGEMENTS}

We would like to thank the following Hungarian beekeepers for providing colonies for our experiment: Imre Bognár (Gelse), András and Ernő Kiss (Varászló), László Papp (Varászló), Ferenc Juráskovics (Nikla), József Palacki (Keszthely), Árpád Kovács (Sávoly), László Balogh (Lábod), László Imre, István Horváth, János Fürst (Nagyatád). We also thank László Orbán for his advice on writing and finalising the manuscript. The publication was supported by the GINOP-2.3.2-15-2016-00054 and EFOP-3.6.3-VEKOP16-2017-00008 projects.

\section{REFERENCES}

Barlow, V. M. and Fell, D. R. (2006): Sampling Methods for Varroa Mites on the Domesticated Honeybee. Virginia State University, Virginia Cooperative Extension Publication, pp. 444-103.

Deutschen Imkerbund (2013): Methodenhandbuch der Arbeitsgemeinschaft Toleranzzucht (Agt). Deutschen Imkerbund, Kirchhain, Germany.

Kolics, É., Mátyás, K., Taller, J., Specziár, A. and Kolics, B. (2020): Contact effect contribution to the high efficiency of lithium chloride against the mite parasite of the honey bee. Insects 11, 333.

Kolics, B., Sajtos, Z., Mátyás, K., Kolics, É., Taller, J. and Baranyai, E. (2019): Lithium chloride - hazard or possibility? 46th APIMONDIA - International Apicultural Congress, Montreal, Quebec, Canada, 8-12 September 2019.

Mozes-Koch, R., Slabezki, Y., Efrat, H., Kalev, H., Kamer, Y., Yakobson, B. A. and Dag, A. (2000): First detection in Israel of fluvalinate resistance in the Varroa mite using bioassay and biochemical methods. Exp. Appl. Acarol. 24, 35-43.

Mutinelli, F., Baggio, A., Capolongo, F., Piro, R., Prandin, L. and Biasion, L. (1997): A scientific note on oxalic acid by topical application for the control of varroosis. Apidologie 28, 461-462.

Rademacher, E. and Harz, M. (2006): Oxalic acid for the control of varroosis in honey bee colonies - a review. Apidologie 37, 98120.

Rosenkranz, P., Aumeier, P. and Ziegelmann, B. (2010): Biology and control of Varroa destructor. J. Invertebr. Pathol. 103, S96S119.

Smithberg, M. and Dixit, P. K. (1982): Teratogenic effects of lithium in mice. Teratology 26, 239-246.

Spivak, M. and Reuter, G. (2005): A Sustainable Approach to Controlling Honey Bee Diseases and Varroa Mites. USDA, Washington, D.C. pp. 1-6.

Spreafico, M., Eördegh, F. R., Bernardinelli, I. and Colombo, M. (2001): First detection of strains of Varroa destructor resistant to coumaphos. Results of laboratory tests and field trials. Apidologie 32, 49-55.

Stanimirovic, Z., Glavinic, U., Ristanic, M., Aleksic, N., Jovanovic, N., Vejnovic, B. and Stevanovic, J. (2019): Looking for the causes of and solutions to the issue of honey bee colony losses. Acta Vet. Beograd 69, 1-31.

Ziegelmann, B., Abele, E., Hannus, S., Beitzinger, M., Berg, S. and Rosenkranz, P. (2018): Lithium chloride effectively kills the honey bee parasite Varroa destructor by a systemic mode of action. Sci. Rep. 8, 683.

Ziegelmann, B., Blumenschein, M., Rein, C., Lang, V., Hannus, S. and Rosenkranz, P. (2019): Varroa treatment of brood-free honey bee colonies with lithium chloride. Paper presented at the 46th APIMONDIA - International Apicultural Congress, Montréal, Québec, Canada, 8-12 September 2019.

Open Access. This is an open-access article distributed under the terms of the Creative Commons Attribution 4.0 International License (https://creativecommons.org/ licenses/by/4.0/), which permits unrestricted use, distribution, and reproduction in any medium, provided the original author and source are credited, a link to the CC License is provided, and changes - if any - are indicated. (SID_1) 